\title{
Effects of Different Riding Surfaces on the Hoof- and Fetlock-acceleration of Horses
}

\author{
Lisa Kruse (Corresponding author) \\ Institute of Animal Breeding and Husbandry, Christian-Albrechts-University \\ Olshausenstraße 40, D-24098 Kiel, Germany \\ E-mail: lkruse@tierzucht.uni-kiel.de \\ Imke Traulsen \\ Institute of Animal Breeding and Husbandry, Christian-Albrechts-University \\ Olshausenstraße 40, D-24098 Kiel, Germany \\ E-mail: itraulsen@tierzucht.uni-kiel.de \\ Joachim Krieter \\ Institute of Animal Breeding and Husbandry, Christian-Albrechts-University \\ Olshausenstraße 40, D-24098 Kiel, Germany \\ E-mail: jkrieter@tierzucht.uni-kiel.de
}

$\begin{array}{ll}\text { Received: November 14, } 2011 & \text { Accepted: December 1, } 2011 \quad \text { Online Published: April 1, } 2012 \\ \text { doi:10.5539/jas.v4n5p17 } & \text { URL: http://dx.doi.org/10.5539/jas.v4n5p17 }\end{array}$

\begin{abstract}
In the traditional equestrian disciplines such as dressage and jumping there is a multitude of riding surface types. Properties of riding surfaces are associated with risk of injury. The aim of the present study was to analyse the sport-functional properties of five different riding surfaces by acceleration measurements on horse's hoof and fetlock. Six riding horses were used. The acceleration data were collected while the horses were trotted by hand on the different surfaces. Larger acceleration values during hoof landing were measured in outdoor arenas compared to indoor arenas. Larger values were associated with a harder surface. The acceleration values of hoof and fetlock were positively correlated. In conclusion differences in the sport-functional properties of various riding surfaces would be demonstrated. Concerning the sensor application it must be noted that the sensor mounting on horse's hoof as well as on horse's fetlock would be suitable for testing riding surfaces.
\end{abstract}

Keywords: Riding surface, Horse, Hoof, Fetlock, Acceleration, Injury risk

\section{Introduction}

Diseases of the locomotor apparatus are a major cause of sport horses' culling and attrition. In addition to other factors, such as the type of horseshoe and the degree of fatigue of the horse, properties of riding surfaces are associated with risk of injury (Barrey, 1999; Pratt, 1997). Studies on racehorses have demonstrated that the hardness of racetrack surfaces has an influence on the risk of limb injury of racehorses. Harder racing surfaces have been associated with an increase in injuries (Williams, Harkins, Hammond, \& Wood, 2001). To assess the effects of different ground surfaces on the horses' limbs, the measurement of hoof-acceleration can be a useful method (Barrey, Landjerit, \& Wolter, 1991; Burn, 2006; Chateau et al., 2009; Gustås, Johnston, \& Drevemo, 2006; Ratzlaff, Wilson, Hutton, \& Slinker, 2005; Setterbo et al., 2009). In previous studies, which deal with sport-functional properties of surfaces, mostly racetrack surfaces (Chateau et al., 2009; Ratzlaff et al., 2005; Setterbo et al., 2009) as well as unusual ground surfaces such as tarmac (Burn, 2006) and sandpaper (Gustås et al., 2006) have been investigated. Further, thoroughbreds (Burn, 2006; Ratzlaff et al., 2005; Setterbo et al., 2009) and standardbred trotters (Chateau et al., 2009; Gustås et al., 2006) have mostly been used in these investigations and in the majority of cases only a few strides performed by a small number of horses have been analysed. 
However, previous studies have also shown a high variability between as well as within horses (Chateau et al., 2009) and the necessity to record a larger number of strides from several horses.

In traditional equestrian disciplines such as dressage and jumping there is a multitude of riding surface types, so that differences in the sport-functional properties of the surfaces, such as hardness and shearing strength, could be expected. For surfaces with footing for dressage or jumping horses, measurement devices, which were easy to use and supplied satisfactory results, were not established in practise. Further, investigations into acceleration data on riding surfaces, which have used several warmblood horses as well as a greater number of strides, have not been yet conducted.

The aim of the present study was to analyse the sport-functional properties of different riding surfaces by acceleration measurement on horses' hoof and fetlock with an easy to handle measurement device. Another objective of this investigation was to record hoof- and fetlock-acceleration simultaneously to compare the measurement results of both sensor applications. In the present investigation different warmblood horses were used for surface testing and the acceleration-time curves were recorded over approximately 65 seconds.

\section{Materials and Methods}

\subsection{Horses and Ground Surfaces}

Six Holsteiner warmblood geldings between the ages of five and six years were used in the present investigation. The body mass of each horse was between $542 \mathrm{~kg}$ and $603 \mathrm{~kg}$ and each had a stick measure between $165 \mathrm{~cm}$ and $177 \mathrm{~cm}$. Furthermore they were shod with standard steel shoes. Each horse was trained to trot by hand on the different surfaces. Five riding surfaces were tested: two outdoor arenas; one with a grass surface (grass outdoor) and one with a sand surface (sand outdoor) as well as three indoor arenas; one with a sand-synthetic fibre surface used for lunging (sand-synthetic indoor I), one with a sand-synthetic fibre surface used for jumping horses (sand-synthetic indoor II) and one with a sand-sawdust surface used for dressage horses (sand-sawdust indoor). All five tested riding surfaces were in good condition and regularly maintained.

\subsection{Device Description}

In the present investigation a motion analysis system developed by Noraxon (Noraxon U.S.A. Inc., Scottsdale, Arizona) was used. The motion analysis system consisted of two small biaxial accelerometers and a measurement station (MyoTrace 400) as well as special software (MyoResearch XP). The accelerometers had a weight of $2.8 \mathrm{~g}$ and a range of $+/-98.1 \mathrm{~m} / \mathrm{s}^{2}$ with a sensitivity of $981 \mathrm{mV} / \mathrm{m} / \mathrm{s}^{2}$. The acceleration data were stated in multiples of acceleration due to gravity $\left(1 \mathrm{~g}=9.81 \mathrm{~m} / \mathrm{s}^{2}\right)$. One accelerometer device was fixed to the lateral hoof wall of the left forelimb (Fig. 1). The other accelerometer device was fixed laterally on the fetlock of the same leg (Fig. 1). Fixation was performed using double sided adhesive tape and fabric tape. The y-axes of the two accelerometers were aligned to the ground and the $\mathrm{x}$-axes were oriented to the direction of movement. The two acceleration devices were connected via a cable with the measurement station. Self-adhesive bandages were used to fix the cables on the horse's limb. The measurement station was fixed to a surcingle, which the horse was wearing during data acquisition. Via Bluetooth the measurement station transferred acceleration data simultaneously to a notebook. The notebook was used for starting and stopping the data acquisition as well as for measurement control. Data acquisition was performed at $1004.03 \mathrm{~Hz}$. A $500 \mathrm{~Hz}$ anti-aliasing filter was included in the motion analysis system.

\subsection{Data Acquisition}

As mentioned before, five riding surfaces were tested. Each surface was tested with the six horses. The data was logged for 65 seconds while the horse was trotted by hand on a defined circle with a diameter of 16 meters. In the first step the horses were adapted to the accelerometer devices. Data acquisition was checked with the notebook and was performed as soon as the horse trotted in a regular cadence. Each run was filmed with a video recorder. The videos were used to calculate the mean speed of each horse on each surface. Therefore, the time, which was needed by the horse for trotting three circles, was stopped and the mean speed was calculated by the following expression:

mean speed $=3 d \pi / t_{S}$, in which $d$ is the diameter of the circle in meters and $t_{S}$ is the time in seconds, which was needed by the horse for trotting three circles.

To reduce the influence of sensor application to data recording, all five surfaces were tested with one horse before the sensors were attached to the next horse, and so on. The order of the tested riding arenas differed from run to run. 


\subsection{Data Processing and Statistical Analysis}

The acceleration-time curves were cut in single hoof strikes by using an algorithm written in MATLAB (MATLAB, version R2010a, the MathWorks Inc., Natrick, Massachusetts). The algorithm detected the stance phase of the hoof where the acceleration of the y-axis approached for minimum $60 \mathrm{~ms}$ near zero. Preliminary tests showed that the largest number of correctly detected stance phases could be found with the mentioned algorithm. In a second step the single hoof strikes were cut into the hoof's take-off and landing phase. In the present study only the landing phase beginning with the second half of the swing phase and ending at the end of the hoof's breaking phase were used for statistical analysis. This approach was chosen because the hoof's landing phase is particularly important for the stress on the horse's limb (Drevemo, Hirtjén, \& Johnston, 1994). Figure 2 shows a part of the acceleration-time curves measured on hoof and fetlock in $y$ - and x-direction. For the evaluation of the sport-functional properties of the riding surfaces six acceleration data sets were used. Besides the analysis of the $y$-axis and $\mathrm{x}$-axis of both acceleration sensors, the total acceleration represented by the resultant vector, which were also used in similar investigations (Chateau et al., 2009; Dallap Schaer, Ryan, Boston, \& Nunamaker, 2006; Ryan, Dallap Schaer, \& Nunamaker, 2006) was considered in this study:

- $\quad y$-axis hoof-acceleration (yHOOF)

- $\quad \mathrm{x}$-axis hoof-acceleration (xHOOF)

- resultant vector of the hoof-acceleration (rHOOF)

- $\quad y$-axis fetlock-acceleration (yFETLOCK)

- $\quad \mathrm{x}$-axis fetlock-acceleration (xFETLOCK)

- resultant vector of the fetlock-acceleration (rFETLOCK)

All six acceleration data sets were cut into single hoof's landing phases with the mentioned MATLAB program, which used the hoof's acceleration-time curves in y-axis direction. Between 61 and 78 strides of each horse on each surface were recorded.

For the acceleration-time curves during the hoof's landing phase of the six mentioned data sets, the root mean square value (RMS) was calculated by the formula $=\sqrt{1 / n \sum_{i=1}^{n} x_{i}{ }^{2}}$, in which $x_{i}$ is the $\mathrm{i}$-th observation of the acceleration signal and $n$ is the total number of observations in the acceleration signal. The RMS-value integrates, in contrast to extreme values, several acceleration values. Barrey et al. (1991) stated that the RMS-value relates to the power content of vibrations during the hoof's breaking phase. Vibrations are associated with damaging effects on the locomotor apparatus of sport horses (Rooney, 1974). Additionally, the absolute value of the maximum deceleration (MAX) during impact, which was associated with the maximum stress on the horse's limb, was determined for each stride. Because of the fact that the MAX-values did not follow a normal distribution for all six data sets, only the maximum deceleration of the y-axis of the hoof-mounted sensor (yMAX) was statistically analysed.

The RMS-values of yHOOF, xHOOF, rHOOF, yFETLOCK, xFETLOCK and rFETLOCK as well as yMAX were statistically analysed by using a mixed model (SAS, version 9.1, SAS Institute inc., Cary, North Carolina). The model included the riding surface as a fixed effect, the horse and the interaction between horse and surface as random effects. The least square means were tested for significant differences between the surfaces including a Tukey-Kramer adjustment for multiple testing. In a second step, the acceleration data of hoof and fetlock were compared. The correlation coefficients for the residuals of the hoof- and fetlock-acceleration were calculated. Further, the correlation between the residuals of the x-axis and the y-axis of both sensors were computed.

\section{Results}

The results of the mixed model showed a highly significant effect $(p<0.01)$ of the fixed effect surface for yMAX and the RMS-values of all six acceleration data sets. The repeatability of the random effect horse was 0.28 for the variable yMAX, between 0.39 and 0.49 for the RMS-values of the hoof-mounted sensor (yHOOF, $\mathrm{xHOOF}, \mathrm{rHOOF}$ ) and between 0.19 and 0.23 for the RMS-values of yFETLOCK, xFETLOCK and rFETLOCK.

Table 1 shows the least square means of the variable yMAX and the RMS-values of the acceleration data measured on hoof (yHOOF, xHOOF, rHOOF) and fetlock (yFETLOCK, xFETLOCK, rFETLOCK). The riding surfaces were sorted according to the size of the least square means of yMAX, starting with the highest value. A higher acceleration value was associated with a higher degree of hardness of the surface. Both outdoor arenas showed higher hoof- and fetlock-acceleration values compared to the values of the three indoor arenas. The number of significant differences, which were determine between the least square means of the riding surfaces, differs among yMAX and the RMS-values of six data sets. The variable yMAX showed four significant 
differences $(p<0.05)$ between the investigated riding surfaces. Concerning the RMS-values of the $y$-axis hoof-acceleration $(y H O O F)$, six significant differences $(p<0.05)$ could be found. Considering the values measured on the y-axis of the fetlock-mounted sensor (yFETLOCK), the three indoor arenas differ significantly $(\mathrm{p}<0.05)$ from the grass surface. Also the sand-synthetic I arena and the sand-sawdust indoor arena were significantly different $(\mathrm{p}<0.05)$ from the sand outdoor arena. Concerning the $\mathrm{x}$-axis of the hoof- and fetlock-acceleration (xHOOF, xFETLOCK) three significant differences between the least square means of the riding surfaces were determined. Therefore, a smaller number of significant differences could be found between the least square means of the $\mathrm{x}$-axis acceleration compared with the $\mathrm{y}$-axis acceleration. Furthermore, it should be noted that for the variable yMAX as well as the RMS-values of the five data sets yHOOF, yFETLOCK, xHOOF, rHOOF and rFETLOCK the acceleration values of the grass outdoor arena differ significantly $(p<0.05)$ from the indoor arenas. Concerning the values of the resultant vector of both sensors (rHOOF, rFETLOCK), the order and the significant differences between the least square means of the riding surfaces are similar to the results of the single axes data sets. There were significant differences $(p<0.05)$ between the grass surface and the indoor arenas, and no significant differences between the indoor arenas (Tab. 1).

The residuals of the variable yMAX and the RMS-values of yHOOF were high positiv correlated $(\mathrm{r}=0.81)$. Further, positive correlations between the residuals of the hoof and fetlock RMS-values for both axes $\left(r_{y-a x i s}=0.43 ; r_{x-a x i s}=0.52\right)$ and the resultant vector $\left(r_{\text {resultant }}=0.63\right)$ were found. Equally, the $x$-axis and the $y$-axis of the hoof-mounted sensor $(\mathrm{xHOOF}, \mathrm{yHOOF})$ were positivly correlated $\left(\mathrm{r}_{\text {hoof }}=0.44\right)$ as well as the values of yFETLOCK and XFETLOCK $\left(r_{\text {fetlock }}=0.68\right)$. All calculated correlations were highly significant $(\mathrm{p}<0.01)$.

Comparing the least square means of both sensor applications, the least square means of the hoof-mounted sensor were higher in the $\mathrm{x}$-axis direction (yHOOF) and for the resultant vector (rHOOF) than the least square means of yFETLOCK and respectively rFETLOCK. Further, the values of the $\mathrm{x}$-axis of both sensors were larger than the values of the $y$-axis of the respective sensor.

\section{Discussion}

The present study was designed to analyse sport-functional properties of different riding surfaces by acceleration measurement on horse's hoof and fetlock.

The measurement system, being used in the present study included two biaxial sensors. The sensors were fixed on the lateral hoof wall and fetlock with the $y$-axes directed to the ground and the x-axes were oriented to the direction of movement. Because of the shape of the hoof, the vertical hoof-acceleration would not be fully recorded. Further, the acceleration of the transversal (medio-lateral) axis would not be acquired. The capture of all three axes seems to be quiet better, but during the hoof impact only a small transversal acceleration could be expected. Equally, similar investigations by Burn (2006), Gustås et al. (2006) and Setterbo et al. (2009) did not integrated the transversal hoof-acceleration.

Further, it must be noted that the used acceleration sensors had a relatively small range compared with accelerometers, being used in earlier investigations (Barrey et al., 1991; Benoit, Barrey, Regnault, \& Brochet, 1993; Burn, 2006; Chateau et al., 2009; Dallap Schaer et al., 2006; Gustås et al., 2006; Ratzlaff et al., 2005). The results of the statistical analysis of the variable yMAX showed that the range was sufficient for measure hoof-acceleration data in slow trot on riding surfaces. But a larger range seems to be more suitable especially for harder surfaces and faster gaits, because among others Burn (2006) measured on average a maximum hoof-acceleration of $17 \mathrm{~g}$ during impact in trot on sand and $504 \mathrm{~g}$ on tarmac.

Additionally, the sampling rate of the acceleration measurement system was relatively low, compared with previous studies (Barrey et al., 1991; Benoit et al., 1993; Burn, 2006; Chateau et al., 2009; Dallap Schaer et al., 2006; Gustås et al., 2006; Ratzlaff et al., 2005). Burn, Wilson, and Nason (1997) concluded that a sampling rate of minimum $2500 \mathrm{~Hz}$ was needed, because more than $98.2 \%$ of the hoof-acceleration signal energy, which was measured in trot on a concrete surface, was below $625 \mathrm{~Hz}$ and over $99 \%$ of the energy was below $1250 \mathrm{~Hz}$. But on riding surfaces, which were investigated in the current study, lower frequencies could be expected, than on a concrete runway. Therefore, a sampling rate of $1000 \mathrm{~Hz}$ seems to be sufficient for data recording and would equally used in similar studies by Setterbo et al. (2009) and Witte, Knill, and Wilson (2004) Advantages of the acceleration sensors, being used in this study, were the wireless data transfer and the possibility to control data acquisition simultaneously using a notebook. Because of the unrestricted recording time it was possible to record a large number of acceleration data. The repeatability of the random effect horse was between 0.19 and 0.49 ; this showed the high variability within horses. These results were in line with Chateau et al. (2009), who demonstrated a high variability within horses in acceleration data during hoof impact on the ground as well as a 
high between-horse variability. Therefore, the recording of a sufficiently large database was necessary for robust statistical results.

In the current study, the order of the least square means of the different riding surfaces was comparable for the six data sets. The number of significant differences, determined by the statistical analysis, varied between yMAX, yHOOF, xHOOF, rHOOF, yFETLOCK, xFETLOCK and rFETLOCK. This outcome could be explained by the different orientation of $\mathrm{x}$ - and $\mathrm{y}$-axes during the hoof's landing phase as well as by the characteristics of impact power during hoof landing. Further, the acceleration values of the $\mathrm{x}$-axis represented the shearing strength, while values of the $y$-axis illustrated the force reduction. In the present investigation the values of the $\mathrm{x}$-axis were larger for both sensors (xHOOF, xFETLOCK) than the respective $y$-axis acceleration. Therefore, the load on the $\mathrm{x}$-axis during hoof landing was higher than in the $\mathrm{y}$-axis direction. However, the consideration of the resultant vector could be useful to reduce the influence of the orientation of the axes during hoof landing and to illustrate the total acceleration.

The highest yMAX-value as well as the highest RMS-values on hoof and fetlock in both directions as well as the resultant vector were recorded on the grass surface and the sand outdoor arena. These results were expected because both surfaces showed a low vertical deformation when the hoof touched the ground. Equally, these results are partly similar to previous investigations. Likewise, Ryan et al. (2006) obtained larger acceleration values measured on a grass paddock compare to an indoor arena and a standard dirt racetrack. Larger acceleration values generally result in increased root mean square values and indicate a higher degree of hardness of the ground surface. Harder track surfaces have also been associated with an increase in injuries (Williams et al., 2001). The sand-sawdust indoor arena in the study is normally used for dressage horses and showed the lowest acceleration values for all six data sets. This outcome could be explained by the larger vertical deformation shown when the hoof touched the ground. Furthermore, arenas with footing for dressage horses are mostly softer than surfaces for jumping horses. Lower acceleration values are associated with a softer surface and a decrease in the stress on the horse's limb. But nevertheless, too soft surfaces could result in injuries on the horse's locomotor system. The levels of yMAX and the RMS-values, which were measured in the current study, were in line with the maximum deceleration and the RMS-values measured by Barrey et al. (1991) on sand, sand-sawdust, gravel-sand and wood chips surfaces. It must be noted that in earlier studies larger hoof-acceleration values during impact in trot were recorded. For example Gustås et al. (2006) recorded vertical hoof-accelerations during trotting (3.0-5.7 m/s) on sand up to approximately $400 \mathrm{~m} / \mathrm{s}^{2}$. The differences between the acceleration values recorded in the present study and values measured in earlier investigations could be explained by differences in the used acceleration sensors, sensor mounting, horses gait and surface properties.

Comparing the values of the hoof- and fetlock-mounted sensor, the fetlock-acceleration (rFETLOCK) showed lower acceleration values than the resultant vector of the hoof-mounted sensor (rHOOF). This outcome was expected, because the fetlock-mounted sensor was fixed on the skin, which was able to attenuate high acceleration amplitudes during hoof landing by skin displacement. Additionally the anatomy of the hoof and the interphalangeal joints (Gustås, Johnston, Roepstorff, \& Drevemo, 2001) as well as the metacarpophalangeal joint buffered the acceleration during the hoof's landing phase to prevent damage caused by high impact of force.

\section{Conclusion}

The present study illustrates that both sensor applications as well as both axes and the resultant vector are suitable for the assessment of the sport-functional properties of riding surfaces. Concerning the riding surfaces it must be noted that the grass outdoor arena showed the highest degree of hardness, while the sand-sawdust indoor arena was the softest surface. A final evaluation whether a riding surface is too hard or too soft could not be done. This questioning could be the subject of further investigations.

\section{References}

Barrey, E. (1999). Methods, Applications and Limitations of Gait Analysis in Horses. Veterinary Journal, 157, 7-22. http://dx.doi.org/10.1053/tvjl.1998.0297

Barrey, E., Landjerit, B., \& Wolter, R. (1991). Shock and vibration during the hoof impact on different track surfaces. In S.G.B. Persson, A. Lindholm, \& L.B. Jeffcott (Eds.), Equine Exercise Physiology 3 (pp.97-106). Davis, CA: ICEEP.

Benoit, P., Barrey, E., Regnault, J. C., \& Brochet, J. L. (1993). Comparison of the damping effect of different shoeing by the measurement of the hoof acceleration. Acta Anatomica, 146, 109-13. http://dx.doi.org/10.1159/000147430 
Burn, J. F. (2006). Time domain characteristics of hoof-ground interaction at the onset of the stance phase. Equine veterinary Journal, 38, 657-663. http://dx.doi.org/10.2746/042516406X159098

Burn, J. F., Wilson, A., \& Nason, G. P. (1997). Impact during equine locomotion: techniques for measurement and analysis. Equine veterinary Journal Supplement, 23, 9-12.

Chateau, H., Robin, D., Falala, S., Pourcelot, P., Valette, J.-P., Ravary, B., et al. (2009). Effects of a synthetic all-weather waxed track versus a crushed sand track on 3D acceleration of the front foot in three horses trotting at high speed. Equine veterinary Journal, 41, 247-251. http://dx.doi.org/10.2746/042516409X394463

Dallap Schaer, B. L., Ryan, C. T., Boston, R. C., \& Nunamaker, D. M. (2006). The horse-racetrack interface: A preliminary study on the effect of shoeing on impact trauma using a novel wireless data acquisition system. Equine veterinary Journal, 38, 664-670. http://dx.doi.org/10.2746/042516406X156389

Drevemo, S., Hirtjén, G., \& Johnston, C. (1994). Drop hammer tests of Scandinavian harness racetracks. Equine veterinary Journal Supplement, 17, 35-38.

Gustås, P., Johnston, C., Roepstorff, L., \& Drevemo, S. (2001). In vivo transmission of impact shock waves in the distal forelimb of the horse. Equine veterinary Journal Supplement, 33, 11-15.

Gustås, P., Johnston, C., \& Drevemo, S. (2006). Ground reaction force and hoof deceleration patterns on two different surfaces at the trot. Equine Comparative Exercise Physiology, 3, 209-216. http://dx.doi.org/10.1017/S147806150667607X

Pratt, G.W. (1997). Model for injury to the foreleg of the Thoroughbred racehorse. Equine veterinary Journal Supplement, 23, 30-32.

Ratzlaff, M. H., Wilson, P. D., Hutton, D. V., \& Slinker, B. K. (2005). Relationships between hoof-acceleration patterns of galloping horses and dynamic properties of the track. American Journal of Veterinary Research, 66, 589-595. http://dx.doi.org/10.2460/ajvr.2005.66.589

Rooney, J. R. (1974). Biomechanics of Lameness (2nd ed.). Huntington, NY: Robert Krieger.

Ryan, C. T., Dallap Schaer, B. L., \& Nunamaker, D. M. (2006). A novel wireless data acquisition system for the measurement of hoof accelerations in the exercising horse. Equine veterinary Journal, 38, 671-674. http://dx.doi.org/10.2746/042516406X156361

Setterbo, J. J., Garcia, T. C., Campbell, I. P., Reese, J. L., Morgan, J. M., Kim, S. Y., et al. (2009). Hoof accelerations and ground reaction forces of Thoroughbred racehorses measured on dirt, synthetic, and turf track surfaces. American Journal of Veterinary Research, 70, 1220-1229. http://dx.doi.org/10.2460/ajvr.70.10.1220

Williams, R. B., Harkins, L. S., Hammond, C. J., \& Wood, J. L. N. (2001). Racehorse injuries, clinical problems and fatalities recorded on British racecourses from flat racing and National Hunt racing during 1996, 1997 and 1998. Equine veterinary Journal, 33, 478-486. http://dx.doi.org/10.2746/042516401776254808

Witte, T. H., Knill, K., \& Wilson, A. M. (2004). Determination of peak vertical ground reaction force from duty factor in the horse (Equus caballus). Journal of Experimental Biology, 207, 3639-3648. http://dx.doi.org/10.1242/jeb.01182 
Table 1. Mean speed of the horses (in $\mathrm{m} / \mathrm{s}$ ) as well as the least square means and standard errors (in $\mathrm{g}$ ) of yMAX and the RMS-values of the acceleration data measured on hoof and fetlock during the hoof's landing phase on the five riding surfaces

\begin{tabular}{|c|c|c|c|c|c|c|c|c|}
\hline & $\begin{array}{l}\text { Mean } \\
\text { speed }\end{array}$ & yMAX & yHOOF & yFETLOCK & xHOOF & xFETLOCK & rHOOF & rFETLOCK \\
\hline Grass outdoor & $\begin{array}{c}3.33 \\
(0.13)\end{array}$ & $\begin{array}{l}7.88^{\left.\mathrm{a}^{*}\right)} \\
(0.58)\end{array}$ & $\begin{array}{l}1.62^{\mathrm{a}} \\
(0.11)\end{array}$ & $\begin{array}{l}1.25^{\mathrm{a}} \\
(0.07)\end{array}$ & $\begin{array}{l}1.81^{\mathrm{a}} \\
(0.13)\end{array}$ & $\begin{array}{l}1.80^{\mathrm{a}} \\
(0.07)\end{array}$ & $\begin{array}{l}2.45^{\mathrm{a}} \\
(0.16)\end{array}$ & $\begin{array}{l}2.20^{\mathrm{a}} \\
(0.09)\end{array}$ \\
\hline Sand outdoor & $\begin{array}{c}2.99 \\
(0.19)\end{array}$ & $\begin{array}{l}7.27^{\mathrm{a}, \mathrm{b}} \\
(0.58)\end{array}$ & $\begin{array}{l}1.56^{\mathrm{a}, \mathrm{b}} \\
(0.11)\end{array}$ & $\begin{array}{l}1.21^{\mathrm{a}, \mathrm{b}} \\
(0.07)\end{array}$ & $\begin{array}{l}1.66^{\mathrm{a}, \mathrm{b}} \\
(0.13)\end{array}$ & $\begin{array}{l}1.76^{\mathrm{a}, \mathrm{b}} \\
(0.07)\end{array}$ & $\begin{array}{l}2.29^{\mathrm{a}, \mathrm{b}} \\
(0.16)\end{array}$ & $\begin{array}{l}2.15^{\mathrm{a}, \mathrm{b}} \\
(0.09)\end{array}$ \\
\hline $\begin{array}{l}\text { Sand-synthetic } \\
\text { indoor I }\end{array}$ & $\begin{array}{c}3.43 \\
(0.22)\end{array}$ & $\begin{array}{l}6.55^{\mathrm{b}, \mathrm{c}} \\
(0.58)\end{array}$ & $\begin{array}{l}1.44^{\mathrm{b}, \mathrm{c}} \\
(0.11)\end{array}$ & $\begin{array}{l}0.99^{\mathrm{c}} \\
(0.07)\end{array}$ & $\begin{array}{l}1.51^{\mathrm{b}} \\
(0.13)\end{array}$ & $\begin{array}{l}1.60^{\mathrm{b}, \mathrm{c}} \\
(0.07)\end{array}$ & $\begin{array}{l}2.11^{b, c} \\
(0.16)\end{array}$ & $\begin{array}{l}1.89^{\mathrm{c}} \\
(0.09)\end{array}$ \\
\hline $\begin{array}{l}\text { Sand-synthetic } \\
\text { indoor II }\end{array}$ & $\begin{array}{c}3.18 \\
(0.32)\end{array}$ & $\begin{array}{c}6.46 b^{b, c} \\
(0.58)\end{array}$ & $\begin{array}{l}1.43^{\mathrm{c}, \mathrm{d}} \\
(0.11)\end{array}$ & $\begin{array}{l}1.06^{\mathrm{b}, \mathrm{c}} \\
(0.07)\end{array}$ & $\begin{array}{l}1.56^{\mathrm{b}} \\
(0.13)\end{array}$ & $\begin{array}{l}1.63^{\mathrm{a}, \mathrm{c}} \\
(0.07)\end{array}$ & $\begin{array}{l}2.13^{b, c} \\
(0.16)\end{array}$ & $\begin{array}{l}1.95^{\mathrm{b}, \mathrm{c}} \\
(0.09)\end{array}$ \\
\hline $\begin{array}{l}\text { Sand-sawdust } \\
\text { indoor }\end{array}$ & $\begin{array}{c}3.37 \\
(0.27)\end{array}$ & $\begin{array}{l}5.46^{\mathrm{c}} \\
(0.58)\end{array}$ & $\begin{array}{l}1.31^{\mathrm{d}} \\
(0.11)\end{array}$ & $\begin{array}{l}0.99^{\mathrm{c}} \\
(0.07)\end{array}$ & $\begin{array}{l}1.47^{\mathrm{b}} \\
(0.13)\end{array}$ & $\begin{array}{l}1.58^{\mathrm{c}} \\
(0.07)\end{array}$ & $\begin{array}{l}1.99^{\mathrm{c}} \\
(0.16)\end{array}$ & $\begin{array}{l}1.87^{\mathrm{c}} \\
(0.09)\end{array}$ \\
\hline
\end{tabular}

${ }^{*}$ Different superscript letters within a column indicate significant differences $(\mathrm{p}<0.05)$

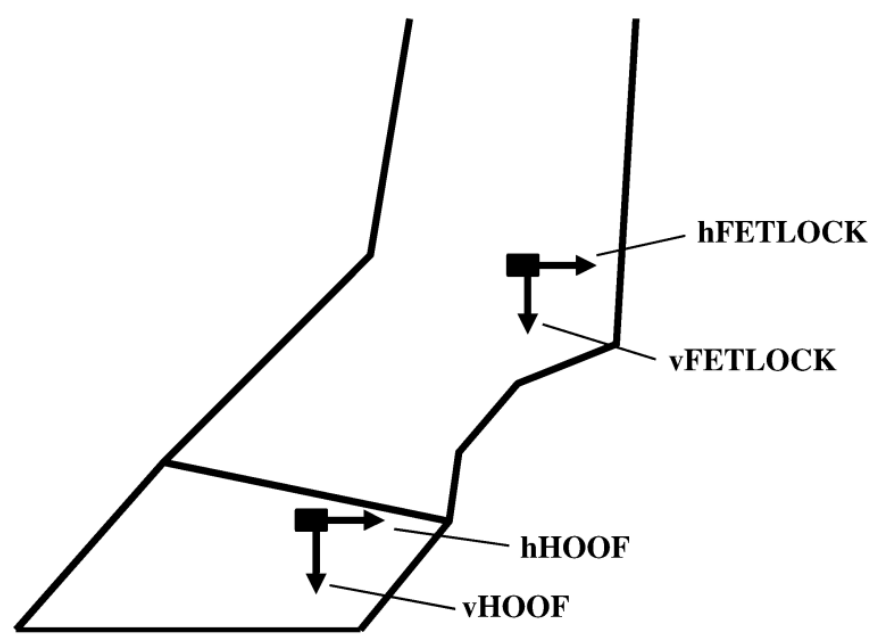

Figure 1. Sensor application and alignment of the axes on hoof and fetlock 

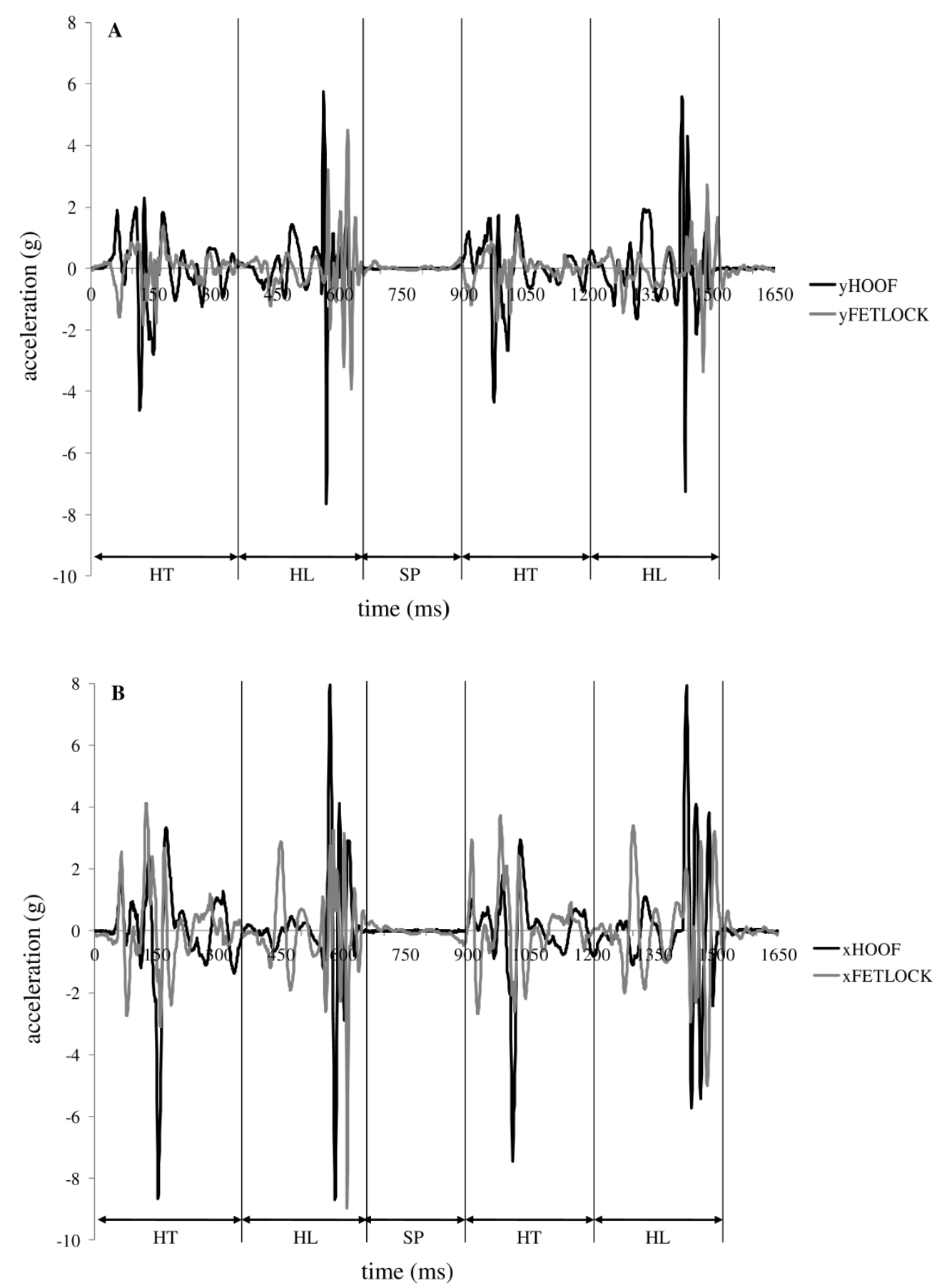

Figure 2. An exemplarily chosen part of the acceleration signal on hoof and fetlock in y-direction (A) and $\mathrm{x}$-direction (B) of horse 5 on the sand outdoor arena (speed $2.98 \mathrm{~m} / \mathrm{s}$ ). HT = hoof's take off phase. HL = hoof's landing phase. $\mathrm{SP}=$ stance phase of the hoof 